\title{
EFEITO DE DIFERENTES ADITIVOS SOBRE OS TEORES DE PROTEÍNA BRUTA, EXTRATO ETÉREO E DIGESTIBILIDADE DA SILAGEM DE MARACUJÁ ${ }^{1}$
}

\author{
Effects of different additives on the content of crude protein, ether extract and \\ coefficient of digestibility of silage of passion fruit residue
}

\author{
Arnaldo Prata Neiva Júnior ${ }^{2}$, José Cleto da Silva Filho 3 , Igor Maximiliano Eustáquio V. Von Tiesenhausen ${ }^{4}$ \\ Gudesteu Porto Rocha ${ }^{7}$, Edílson Rezende Cappelle ${ }^{5}$, Cristóvão Colombo de Carvalho Couto Filho ${ }^{6}$
}

\begin{abstract}
RESUMO
Com o objetivo de avaliar os teores de proteína bruta, extrato etéreo e a digestibilidade "in vitro" da matéria seca (DIVMS) da silagem de resíduo de maracujá em mistura com diferentes aditivos, em níveis crescentes de adição, foi conduzido este estudo. O delineamento experimental utilizado foi o inteiramente casualizado, com quatro repetições, sendo os tratamentos dispostos em um esquema fatorial do tipo $(3 \times 4)+1$, sendo três aditivos (bagaço de cana (BC), casca de café (CC) e sabugo de milho (SM) em quatro níveis de adição $(10,15,20$ e $25 \%)$ e um tratamento testemunha (resíduo de maracujá puro ensilado). O material experimental foi ensilado em silos de PVC adaptados com válvula tipo "Bunsen" com capacidade para aproximadamente $3 \mathrm{~kg}$ cada. Apenas o aditivo CC promoveu aumento dos teores de PB. O aditivo CC foi o que mais contribuiu para a redução dos teores de EE. Os valores de DIVMS permitiram classificar as silagens como de boa ou média qualidade, à exceção da silagem aditivada de SM.
\end{abstract}

Termos para indexação: Resíduos agroindustriais, maracujá, bagaço de cana, casca de café, sabugo de milho, digestibilidade.

\begin{abstract}
Aiming to evaluate the content of crude protein, ether extract and the coefficient of "in vitro" dry matter digestibility (IVDMD) of passion fruit residue silage in mixture with different additives at increasing levels of addition, this study was undertaken. The experimental design utilized was the completely randomized, with four replicates. The treatments were arranged in a factorial scheme of the (3 x 4) + 1 type, with three treatments as follow (sugar cane bagasse (CB), coffee hulls (HC) and corn cob (CC) at four levels of addition $(10,15,20$ and $25 \%)$ and a control treatment (ensiled unmixed passion fruit residue). The experimental material was ensiled in PVC silos, fitted with a "Bunsen" type valve, with a capacity of about $3 \mathrm{~kg}$ each. Only the additive $\mathrm{CH}$ increased in the crude protein contents. $\mathrm{CC}$ was the one which contributed to the reduction of ether extract contents. The values of IVDMD allowed to classify the silages as good or of medium quality, except the silage which additive was CC.
\end{abstract}

Index terms: Agroindustrial residue, passion fruit, sugar cane bagasse, coffee hulls, corn cob, digestibility.

(Recebido em 3 de junho de 2005 e aprovado em 6 de março de 2006)

\section{INTRODUÇÃO}

O processamento industrial de produtos agrícolas no Brasil, para a extração de sucos, polpas e óleos, gera uma grande quantidade de subprodutos, constituídos principalmente por sementes, cascas e polpa. O beneficiamento do maracujá, por sua vez, produz uma quantidade de resíduos que corresponde, aproximadamente, de 65 a $70 \%$ do total da fruta. O Brasil é o maior produtor de maracujá amarelo do mundo. Segundo o IBGE (2004), a produção dessa fruta no ano de 2002 foi de aproximadamente 480.000 toneladas.

Em virtude do Brasil ser um país marcado pela estacionalidade da produção de forragens, fator que constitui o principal entrave na exploração pecuária nacional, busca-se, através de técnicas de conservação de alimento, a obtenção de índices produtivos satisfatórios. Nesse contexto, é indiscutível o papel da silagem como volumoso suplementar em períodos de escassez de forragem.

A ensilagem de resíduos provenientes da agroindústria frutícola vem surgindo como uma alternativa às culturas tradicionais, tendo como vantagem um baixo custo de aquisição do material a ser ensilado. Além disso, o aproveitamento destes resíduos contribui para minimizar o impacto causado pelo acúmulo destes resíduos no meio ambiente.

\footnotetext{
${ }^{1}$ Parte da Dissertação de mestrado do primeiro autor.

'2Zootecnista, MSc. em Zootecnia - Professor do CEFET/Rio Pomba-Rua José Sebastião da Paixão s/n-36.180-000-Rio Pomba, MG- apnjrzoo@yahoo.com.br 3Professor do Departamento de Zootecnia - Universidade Federal de Lavras/UFLA - Cx. P. 3037 - 37.200-000 - Lavras, MG - cleto@ufla.br

${ }^{4}$ Professor aposentado do Departamento de Zootecnia - Universidade Federal de Lavras/UFLA - Cx. P. 3037 - $37.200-000$ - Lavras, MG.

${ }^{5}$ Engenheiro Agrônomo DSc. em Zootecnia - Professor do CEFET/Rio Pomba - Rua José Sebastião da Paixão s/n - 36.180-000 - Rio Pomba, MG edilson.cappelle@bol.com.br

${ }^{6}$ Médico Veterinário MSc. em Zootecnia - Fiscal Agropecuário/Agência Agropecuária do Maranhão - Rua Manoel Gonçalves, 710 - Centro - Caxias, MA coutofil@yahoo.com.br

${ }^{7}$ Professor do Departamento de Zootecnia - Universidade Federal de Lavras/UFLA - Cx. P. 3037 - 37.200-000 - Lavras, MG - gudesteu@ufla.br
} 
Com o objetivo de avaliar os teores de proteína bruta, extrato etéreo e a digestibilidade in vitro da matéria seca do resíduo de maracujá ensilado com diferentes aditivos, em níveis crescentes de adição, foi conduzido este estudo.

\section{MATERIAL E MÉTODOS}

O trabalho foi conduzido no Departamento de Zootecnia/UFLA, Lavras - MG. O delineamento experimental foi o inteiramente casualizado (DIC), com 13 tratamentos e quatro repetições. Os tratamentos foram dispostos em um esquema fatorial com tratamento adicional do tipo $(3 \times 4)+1$, três aditivos (bagaço de cana - BC, casca de café - CC e sabugo de milho - SM), quatro níveis de utilização $(10,15,20$ e 25\%), com um tratamento testemunha (resíduo de maracujá puro ensilado). O resíduo de processamento do maracujá foi concedido pela empresa Bela Ischia, situada no município de Astolfo Dutra-MG, e os aditivos foram fornecidos por produtores de Rio Pomba e Lavras, Minas Gerais.

O resíduo de processamento do maracujá, constituído por casca e sementes, juntamente com os aditivos, que passaram previamente por um processo de desintegração (BC e CC) ou trituração (SM), foram levados para um galpão onde se realizou a ensilagem. Para tanto, foram utilizados silos de PVC com diâmetro de $10 \mathrm{~cm}$ e altura de $50 \mathrm{~cm}$, adaptados com válvula tipo "Bunsen", com capacidade para aproximadamente $3 \mathrm{~kg}$ de silagem. $\mathrm{O}$ resíduo de maracujá destinado à produção da silagem testemunha foi imediatamente ensilado. Os aditivos e o resíduo de maracujá foram pesados separadamente e misturados no momento da ensilagem, sendo cada aditivo utilizado em níveis de adição de 10, 15, 20 e 25\%. A compactação dos materiais ensilados foi feita manualmente com auxílio de uma barra de ferro. Em seguida, estes foram fechados com tampas de PVC dotadas de válvula tipo "Bunsen" e vedados com fita crepe. Após 70 dias os silos foram abertos, sendo desprezadas as porções das extremidades de cada silagem. O material a ser analisado foi homogeneizado e amostrado, sendo que parte da amostra foi conservada em freezer e a outra foi levada para uma estufa de ventilação forçada, na qual permaneceu a 65 "o"C por 120 horas, em virtude da alta umidade do material. Posteriormente, estas amostras foram moídas e armazenadas em potes plásticos devidamente identificados.

As análises dos teores de proteína bruta (PB), extrato etéreo (EE) e da digestibilidade "in vitro" da matéria seca foram realizadas conforme metodologias descritas por Silva (1998). Para a condução do ensaio de digestibilidade "in vitro" da matéria seca, uma fêmea Jersey não lactante, com peso aproximado de $400 \mathrm{~kg}$, foi usada como doadora de líquido ruminal. Esse animal passou inicialmente por um período de adaptação de 14 dias, recebendo a silagem experimental que era fornecida "ad libitum". Esta foi produzida em tambores de $200 \mathrm{~L}$, sendo aditivada com um "pool" dos diferentes aditivos no nível de adição intermediário de $15 \%$.

Os dados experimentais foram analisados estatisticamente pelos procedimentos de análise de variância, por meio do programa estatístico Sistema de Análise de Variância para Dados Balanceados (SISVAR), desenvolvido por Ferreira (2000).

O estudo comparativo das médias dos tratamentos foi realizado pelo teste de Student-Newman-Keuls, a 5\% de probabilidade. Para os fatores níveis de aditivos e desdobramento da interação aditivos $\mathrm{X}$ níveis, foi efetuado o estudo de regressão quando ocorreu significância no teste F.

\section{RESULTADOS E DISCUSSÃO}

Os resultados referentes à composição bromatológica dos aditivos e do resíduo de maracujá estão apresentados na Tabela 1 .

Quanto ao teor de PB, observou-se, para o bagaço de cana, um valor próximo ao encontrado por Evangelista (2001) (2,4\%). Santos (1995) determinou, para o bagaço de cana, a seguinte composição química: $\mathrm{MS}=74,36 \%$, $\mathrm{PB}=2,17 \%, \mathrm{FDN}=70,09 \%, \mathrm{FDA}=52,28 \%, \mathrm{EE}=2,48 \%$ e $\mathrm{EB}=4160,35 \mathrm{Kcal} / \mathrm{Kg}$. Mattos (1987) relatou que os teores médios de FDN e EE do bagaço de cana são 84 a $88 \%$ e 0,1 a $0,3 \%$, respectivamente.

$\mathrm{O}$ aditivo sabugo de milho apresentou um teor de PB um pouco mais baixo do que o valor encontrado para o bagaço de cana. Cruz (1992) encontrou para o sabugo de milho a seguinte composição bromatológica: $42,8 \%$ de FDA; 37,7\% de CEL; 7,3\% de LIG.

A casca de café apresentou um teor de PB mais alto que os demais aditivos utilizados e semelhante aos valores relatados por outros autores (BARCELOS, 2000; SOUZA et al., 2003; TEIXEIRA, 1999).

As diferenças observadas nos valores descritos na Tabela 1 em relação aos autores citados, podem ser devido à época e umidade do ar, bem como tempo e local de armazenamento dos resíduos agrícolas.

As silagens experimentais apresentaram boas características, como odor agradável, coloração amarelada, cheiro característico do fruto, textura firme e ausência de fungos. Notou-se coloração escura nas silagens, em que houve adição de casca de café, fenômeno este mais acentuado na silagem de $75 \%$ de resíduo do fruto de maracujá $+25 \%$ de casca de café. 
Com relação ao teor de $\mathrm{PB}$, verificaram-se diferenças entre os aditivos e níveis $(\mathrm{P}<0,01)$ e a interação de níveis $\mathrm{x}$ aditivos $(\mathrm{P}<0,01)$.

Para os aditivos bagaço de cana e sabugo de milho, foi observado um decréscimo linear $(\mathrm{P}<0,01)$ no teor de $\mathrm{PB}$ de 9,68 para $8,1 \%$ e 7,50 para $6,04 \%$, respectivamente, à medida que se elevaram os níveis de adição de 10 para $25 \%$ (Figura 1 ). Na adição de casca de café foi observado um aumento linear $(\mathrm{P}<0,01)$ no teor de
PB de 11,49 para $12,42 \%$, à medida que se elevaram os níveis de adição de $10 \%$ para $25 \%$ (Figura 1). Isto é explicado pelo teor mais elevado de PB da casca de café $(10,20 \%)$ em relação ao sabugo de milho $(2,40 \%)$ e bagaço de cana $(2,63 \%)$.

Os resultados referentes aos teores de proteína bruta, extrato etéreo e digestibilidade in vitro da matéria seca das silagens de resíduo de maracujá em mistura com os diferentes aditivos são apresentados na Tabela 2 .

TABELA 1 - Teores de matéria seca (MS), proteína bruta (PB), fibra em detergente neutro (FDN), fibra em detergente ácido (FDA), celulose (CEL), lignina (LIG), extrato etéreo (EE), energia bruta (EB), na MS dos aditivos bagaço de cana (BC), casca de café (CC), sabugo de milho (SM) antes da ensilagem e do resíduo de maracujá (RM).

\begin{tabular}{lcccccccc}
\hline Aditivos & $\begin{array}{c}\text { MS } \\
(\boldsymbol{\%})\end{array}$ & $\begin{array}{c}\text { PB } \\
(\boldsymbol{\%})\end{array}$ & $\begin{array}{c}\text { FDN } \\
\mathbf{( \% )}\end{array}$ & $\begin{array}{c}\text { FDA } \\
(\boldsymbol{\%})\end{array}$ & $\begin{array}{c}\text { CEL } \\
(\boldsymbol{\%})\end{array}$ & $\begin{array}{c}\text { LIG } \\
\mathbf{( \% )}\end{array}$ & $\begin{array}{c}\text { EE } \\
(\boldsymbol{\%})\end{array}$ & $\begin{array}{c}\text { EB } \\
(\mathbf{K c a l} / \mathbf{K g})\end{array}$ \\
\hline RM & 23,70 & 8,65 & 58,55 & 37,18 & 24,88 & 9,96 & 4,87 & 4477,37 \\
BC & 69,15 & 2,63 & 83,10 & 52,44 & 38,28 & 13,69 & 1,39 & 4169,65 \\
CC & 89,44 & 10,20 & 73,15 & 51,16 & 39,21 & 10,80 & 1,37 & 4172,68 \\
SM & 91,73 & 2,40 & 92,20 & 46,44 & 28,99 & 16,04 & 0,53 & 4091,98 \\
\hline
\end{tabular}

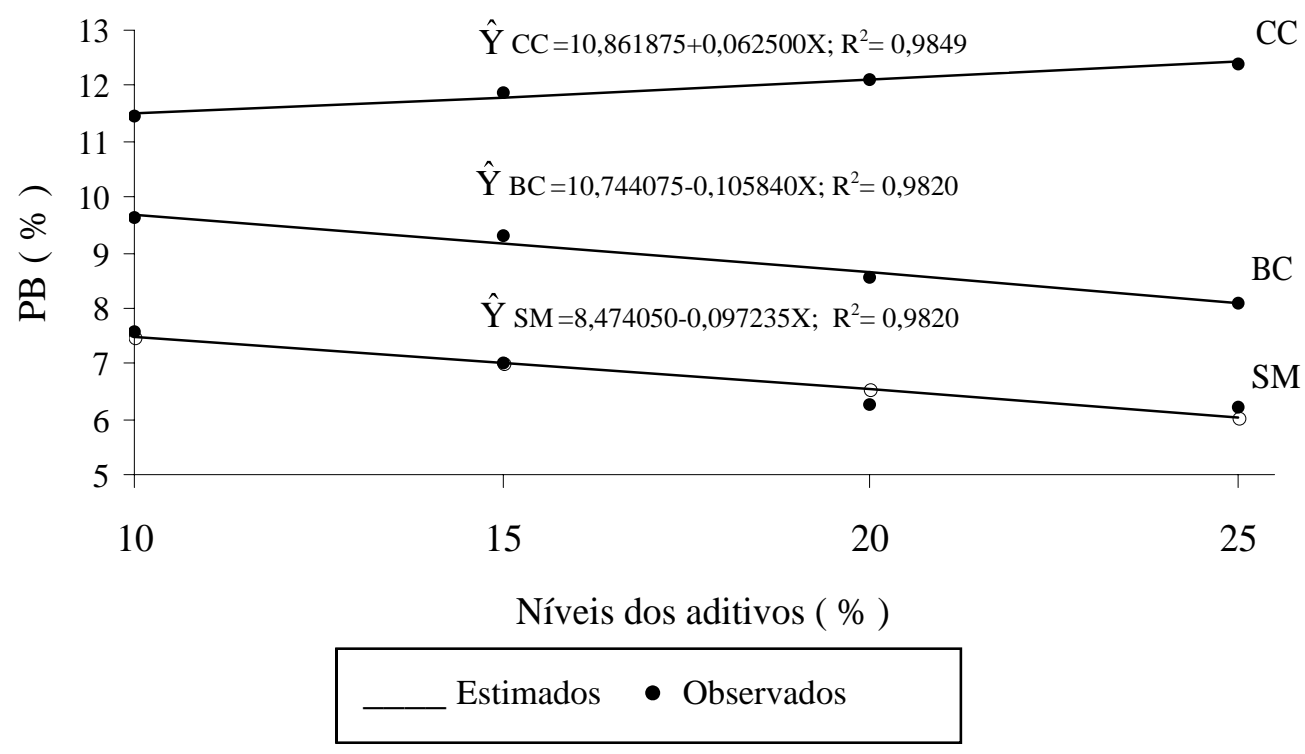

FIGURA 1 - Representação gráfica, equação de regressão e coeficiente de determinação dos teores de proteína bruta (PB) das silagens do resíduo do fruto de maracujá em função dos níveis de adição dos aditivos bagaço de cana (BC), casca de café (CC) e sabugo de milho (SM). 
TABELA 2 - Médias dos teores de proteína bruta (PB), extrato etéreo (EE) e digestibilidade "in vitro" da matéria seca (DIVMS) das silagens de resíduo de maracujá aditivadas com bagaço de cana (BC), casca de café (CC) e sabugo de milho (SM) nos diferentes níveis de adição.

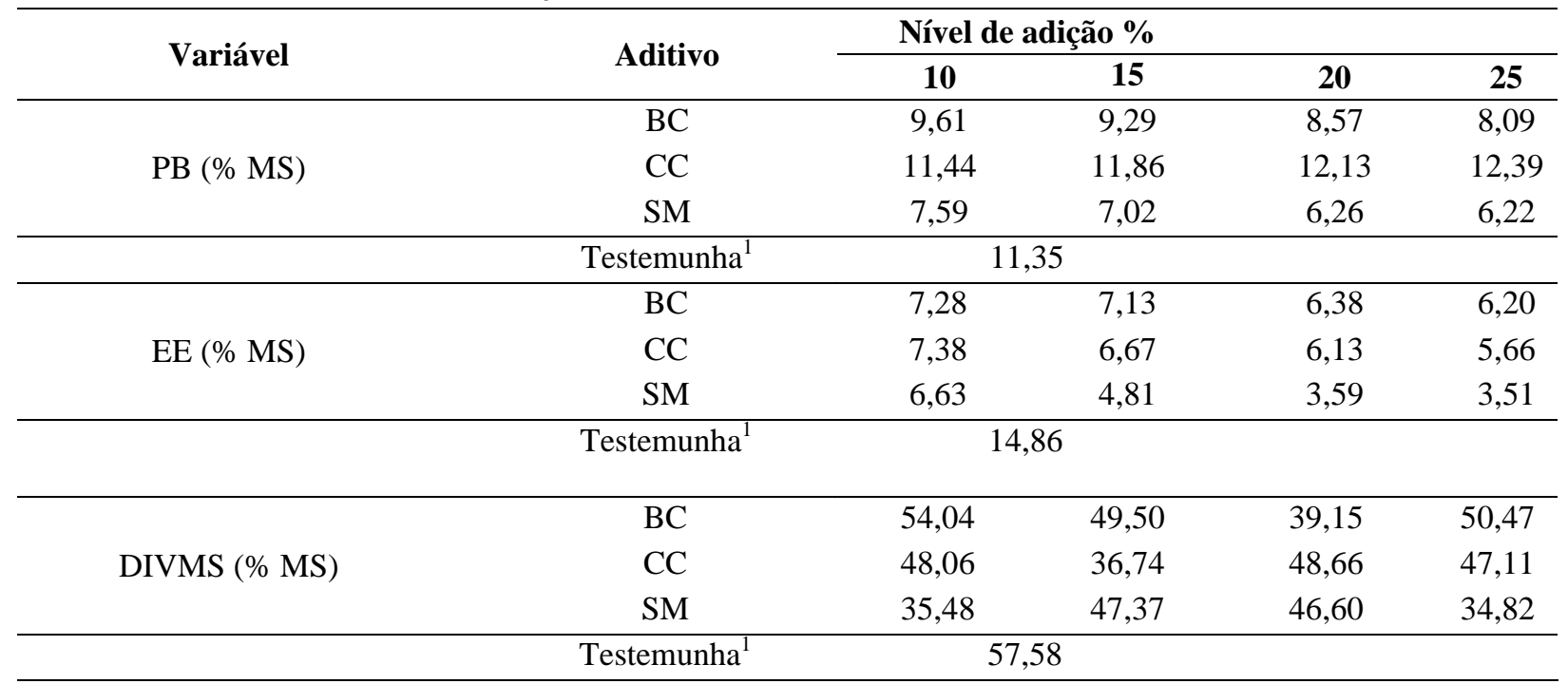

${ }^{1}$ Resíduo de maracujá puro ensilado.

No geral, as concentrações de proteína bruta na MS observadas neste trabalho estão acima do mínimo exigido pelos ruminantes, cujo valor é de $7 \%$ na dieta, conforme relatado por Church (1988).

Com relação ao teor de EE, verificaram-se diferenças entre os aditivos e níveis $(\mathrm{P}<0,01)$, e a interação de aditivos $\mathrm{x}$ níveis $(\mathrm{P}<0,01)$.

Para os aditivos bagaço de cana e casca de café, foi observado um decréscimo linear $(\mathrm{P}<0,01)$ no teor de EE de 7,34 para $6,15 \%$ e de 7,32 para $5,60 \%$, respectivamente, à medida que se elevaram os níveis de adição de 10 para $25 \%$.

Quanto à avaliação dos níveis de aditivos adicionados nas silagens de resíduo do fruto de maracujá, pode-se verificar que nas silagens com associação dos diferentes aditivos foram verificados menores valores de extrato etéreo do que aqueles observados na silagem com $100 \%$ de resíduo do fruto de maracujá. Esse fato é explicado pelo mais elevado teor de EE da silagem com $100 \%$ de resíduo do fruto de maracujá em relação às demais (Tabela 2).

Verifica-se que a concentração de extrato etéreo para todas as silagens estudadas (Tabela 2), exceto a silagem com $100 \%$ de resíduo do fruto de maracujá $(14,86 \%)$ está abaixo do limite de $8 \%$ de EE, recomendado por McGuffey \& Schingoethe (1980), para que não ocorra redução na ingestão de alimento, diminuindo o desempenho animal.

Notou-se, ainda, que, nas silagens com $100 \%$ de resíduo do fruto de maracujá, o teor de extrato etéreo foi próximo ao valor observado por Henrique et al. (1998), com $14,30 \%$, quando trabalharam com silagem de girassol. Já Santos (1995) encontrou, para a silagem do resíduo do fruto de maracujá, teor de $12,14 \%$ de extrato etéreo.

Foram encontradas diferenças entre os aditivos e os níveis de adição $(\mathrm{P}<0,01)$. No geral, as adições de bagaço de cana, casca de café e sabugo de milho reduziram a digestibilidade in vitro da matéria seca em relação à silagem com $100 \%$ de resíduo de maracujá (Tabela 3). Nota-se também que os menores valores de DIVMS foram observados nas silagens de resíduo do fruto do maracujá com sabugo de milho e que à medida em que aumentaramse os níveis de adição de 10 para $25 \%$, os valores de DIVMS decresceram.

Comparando-se as médias da DIVMS dos três aditivos, verificou-se maior valor para o bagaço de cana $(50,12 \%)$, seguido pela casca de café $(47,82 \%)$ e pelo sabugo de milho $(36,55 \%)$, sendo que os três aditivos diferiram entre si (P 0,01).

Rezende et al. (1999) verificaram coeficientes de DIVMS de 58 e $56 \%$ para a silagem de milho e girassol, respectivamente. 
TABELA 3 - Digestibilidade in vitro da matéria seca (DIVMS) das silagens de resíduo do fruto de maracujá com bagaço de cana, casca de café e sabugo de milho.

\begin{tabular}{lc}
\hline \multicolumn{1}{c}{ Aditivo } & DIVMS (\%) \\
\hline Sabugo de milho & $36,55 \mathrm{c}$ \\
Casca de café & $47,82 \mathrm{~b}$ \\
Bagaço de cana & $50,12 \mathrm{a}$
\end{tabular}

Médias seguidas por mesma letra são estatisticamente iguais, pelo teste SNK, a 5\% de probabilidade.

\section{CONCLUSÕES}

$\mathrm{O}$ aditivo casca de café foi o único que promoveu elevações dos teores de proteína bruta das silagens.

De maneira geral, os teores de extrato etéreo das silagens aditivadas encontram-se abaixo do percentual máximo permitido na dieta de ruminantes e os valores de digestibilidade "in vitro" da matéria seca classificam as silagens estudadas como de boa ou média qualidade.

\section{REFERENCIAS BIBLIOGRÁFICAS}

BARCELOS, A. F. Parâmetros bromatológicos, frações de carboidratos e degradabilidade in vitro da casca e da polpa de café (Coffea arábica L.). 2000. 96 p. Tese (Doutorado em Nutrição de Ruminantes) - Universidade Federal de Lavras, Lavras, 2000.

CHURCH, D. C. The ruminant animal digestive physiology and nutrition. New Jersey: Prentice Hall, 1988. 564 p.

CRUZ, G. M. Utilização dos restos de culturas e palhas na alimentação de ruminantes. In: SIMPÓSIO UTILIZAÇÃO DE SUBPRODUTOS AGROINDUSTRIAIS E RESÍDUOS DE COLHEITA NA ALIMENTAÇÃO DE RUMINANTES, 1992, São Carlos. Anais... São Carlos: Embrapa, 1992. p. 99-121.

EVANGELISTA, A. R. Aproveitamento de resíduos da fabricação da aguardente. In: CARDOSO, M. das G. (Ed.). Produção de aguardente de cana-de-açúcar. Lavras: UFLA, 2001. p. 128-151.

FERREIRA, D. F. Análises estatísticas por meio do Sisvar para Windows versão 4.0. In: REUNIÃO ANUAL DA REGIÃO BRASILEIRA DA SOCIEDADE
INTERNACIONAL DE BIOMETRIA, 45., 2000, São Carlos. Anais... São Carlos: UFSCar, 2000. p. 255-258.

HENRIQUE, W.; ANDRADE, J. B.; SAMPAIO, A. A. M. Silagem de milho, sorgo, girassol e suas consorciações: II. composição bromatológica. In: REUNIÃO ANUAL DA SOCIEDADE BRASILEIRA DE ZOOTECNIA, 35., 1998, Botucatu. Anais... Botucatu: SBZ, 1998a. p. 379-381.

INSTITUTO BRASILEIRO DE GEOGRAFIA E ESTATÍSTICA. IBGE. Disponível em: <http:// www.ibge.gov.br>. Acesso em: 9 nov. 2004.

MATTOS, W. R. S. Utilização do bagaço de cana-de-açúcar na alimentação de ruminantes. In: CONGRESSO PAULISTA DE AGRONOMIA, 6., 1987, Piracicaba. Anais... Piracicaba: [s.n.], 1987. p. 99-112.

McGUFFEY, R. K.; SCHINGOETHE, D. J. Feeding value of high oil variety of sunflowers as silage to lactating dairy cows. Journal of Dairy Science, Champaign, v. 63, n. 7, p. 1109-1113, July 1980.

REZENDE, A. V.; EVANGELISTA, A. R.; BERNARDES, T. F. Valor nutritivo de silagem mista de girassol (Helianthus annus L.) e milho (Zea mays L.). In: REUNIÃO ANUAL DA SOCIEDADE BRASILEIRA DE ZOOTECNIA, 36., 1999, Porto Alegre. Anais... Porto alegre: SBZ, 1999. p. 23.

SANTOS, M. A. S. Valor nutritivo de silagens de resíduo de maracujá (Passiflora edulis, Deuger), ou em mistura com casca de café (Coffea arábica, L.), bagaço de cana (Saccharum officinarum, L.) e palha de feijão (Phaseolus vulgaris, L.). 1995. 56 f. Dissertação (Mestrado em Zootecnia) - Universidade Federal de Lavras, Lavras, 1995.

SILVA, D. J. Análise de alimentos: métodos químicos e biológicos. 2. ed. Viçosa: UFV, 1998. 166 p.

SOUZA, A. L.; BERNADINO, F. S.; GARCIA, R. Valor nutritivo de capim-elefante (Pennisetum purpureum Schum.) com diferentes níveis de casca de café. Revista Brasileira de Zootecnia, Viçosa, v. 32, n. 4, p. 828-883, 2003.

TEIXEIRA, M. N. M. Determinação da degradabidade in situ das diferentes frações da casca do grão de três cultivares de café (Coffea arábica L.). 1999. Dissertação (Mestrado em nutrição de Ruminantes) - Universidade Federal de Lavras, Lavras, 1999. 